\title{
NOVAS TECNOLOGIAS: \\ a Intranet como fator de mudança para as \\ unidades de informação
}

\section{Claudia Lopes}

Resumo

Nesta última década, tanto as organizações quanto seres humanos vivem uma época de mudanças cada vez mais rápidas, exigindo em nível de indivíduos e de profissionais uma disponibilidade de aprender e de se adaptar a esses novos tempos. Em relação à área da informação, este processo não deve ser ignorado, já que dele depende a sobrevivência tanto das unidades de informação quanto do efetivo exercício de suas atividades. Sendo necessário, mais do que nunca, que os profissionais da informação repensem suas atividades e posturas. Dentro deste contexto surge a possibilidade de utilizar a Intranet como um instrumento de propagação e melhoria do atendimento, produtos e serviços oferecidos pelas unidades de informação.

\section{Palavras chave}

Novas tecnologias; Tecnologia da informação; Internet; Intranet; Profissional da Informação.

Atualmente, vivenciamos um dos momentos da História da Humanidade onde as mais rápidas mudanças estão ocorrendo nos campos científico, tecnológico, político e social. Mudanças na estrutura global como um todo, que levariam décadas para influenciar boa parte da população mundial, hoje, podem ocorrer em instantes através das transmissões da mídia internacional. O que mais se pode dizer? - O mundo está mudando, e rápido!

É necessário aprender a conviver com essas mudanças, pois "neste mutável mundo de hoje, em que tudo acontece com uma rapidez incrível, só resta mesmo uma saída, tanto para as organizações como para os indivíduos, - ousar/mudar - considerando-se que na atualidade apenas uma certeza existe: a de que a mudança é a única coisa constante em nossos dias" (MÜLLER, 1995).

O fator de risco para as mudanças/inovações pode ser elevado às bibliotecas ou unidades de informação, porém a manutenção do "status quo", favorecendo a obsolescência, é um risco ainda maior. Mas não se pode falar de mudanças como se elas só alterassem ou só fossem necessárias para a estrutura organizacional; a mudança comportamental de cada indivíduo deve ser complementar às mudanças da organização.

A necessidade de atualização contínua é valida e indispensável, tanto no plano pessoal como no âmbito das organizações. Para estas, a tecnologia da informação fornece as possibilidades de permanentes atualização e integração dos negócios, visto que potencializa o processo de difusão, disseminação e transferência de informações (VALLE, 1996).

Para as bibliotecas ou unidades de informação, as novas tecnologias atuam como catalisadores de mudanças particularmente importantes (LEVACON, 1997). 
Segundo Guinchart (1994), podem-se definir "novas tecnologias" como sendo um conjunto de equipamentos, de procedimentos e de métodos utilizados no tratamento da informação e da comunicação. Porém, com as novas tecnologias, a relação entre o profissional - neste caso o profissional da informação - nem sempre foi amigável.

Quando do início da utilização do computador nas bibliotecas e centros de informação, este era visto como um intruso ameaçador. Atualmente esta visão não pode ser compartilhada pelo profissional de informação, já que a sociedade exige em nível de tempo, exaustividade e especificidade, que cada vez mais, este profissional lance mão de recursos tecnológicos da área de informática e telecomunicações para satisfazer a sua clientela.

Após a Segunda Guerra Mundial, com o advento da tecnologia, a produção e disseminação da informação multiplicou-se de forma estrondosa. Nesta mesma época, entra em voga a utilização da palavra "informação" como termo tecnológico para definir qualquer coisa que fosse transmitida por um canal elétrico ou mecânico (WURMAN, 1991). Hoje, sua utilização se tornou mais genérica. Tudo que se vê, se ouve, se fala, ou se sente é rotulado de informação. Mas na verdade, tudo isto não passa de dado, às vezes nem isto. Pois, segundo Belkin e Robson (apud FREIRE, 1995), "informação é o que é capaz de transformar estruturas" e, conforme González de Gómez (1995) deve ser compreendida "como um operador de relação ou como indicador de mediação, num agir relacionante: ver, julgar, conhecer, fazer, comunicar".

O profissional da informação deve perceber que a informação, passou a ser tanto objeto de estudo, como também de trabalho, sendo necessário para isto, readequar os processos, bem como seus objetivos profissionais. "A sobrevivência da biblioteca (ou qualquer que seja seu nome) e o efetivo exercício de suas atividades dependem não somente de boas idéias, mas de cuidadosa atenção sobre como esta mudança será implantada e gerenciada" (MARCHIORI, 1997)

O foco da tecnologia da informação a princípio centrava-se na transmissão e no armazenamento, gerando o crescimento dramático de dados e permitindo a disseminação global da informação quase que instantânea por meio de "modens", satélites, fibras ópticas, etc., diluindo assim, não só as barreiras entre os indivíduos, mas também as barreiras físicas e geográficas entre eles.

Porém, ao entendermos a tecnologia da informação como os meios utilizados pelas empresas produtivas para alavancar e potencializar o processo de criação e desenvolvimento de capacitação tecnológica Morton (apud VALLE, 1996), compreenderemos o porquê da mudança do seu foco, que está se deslocando para os serviços de apoio à interface cliente / equipamento. As máquinas, por si só, não são mais centrantes e sim, a capacidade de processar todo o fluxo de dados e informações com que somos literalmente bombardeados todos os dias. É importante perceber que à medida que a tecnologia, principalmente a de transmissão da informação, torna-se cada vez mais sofisticada, a possibilidade do indivíduo conseguir processar torna-se menor. Por exemplo, no que diz respeito à interface dos sistemas de recuperação da informação, a princípio eles se baseavam em comandos, tornando-se confusas, de difícil entendimento e impenetráveis pelo usuário inexperiente. Para facilitar e vencer essas dificuldades, foram adotadas as interfaces baseadas em "menus". Atualmente, é cada vez mais freqüente o uso de 
interfaces gráficas.

A possibilidade de acessar informações, a partir de todo e qualquer computador pessoal, está revolucionando a relação entre os usuários e a informação, permitindo cada vez mais, novas e criativas maneiras de utilizá-las.

Através da computação e da teletransmissão, hoje, a Internet coloca à disposição do cidadão comum a possibilidade da comunicação imediatizada por computadores, elevando a um nível de poder social altamente amplificado e, às empresas, possibilidades "cósmicas" de negócios. É indiscutível as funções e a importância da Internet na vida das pessoas, empresas e instituições. Porém, além de dar atenção ao potencial econômico do "World Wide Web", as empresas estão descobrindo que uma rede privada (Intranet), baseada nos mesmos padrões da Internet, é uma ferramenta poderosa, um dos instrumentos mais importantes do momento para mudanças na administração, na estrutura organizacional e no comportamento dos indivíduos de sua equipe.

Mais do que um modismo, a Intranet possibilita às empresas criar internamente "miniaturas" da rede mundial, dotadas das mesmas facilidades e com uma gama de aplicações (e-mail, grupos de discussão, tráfego de documentos, etc.) que superam, em muito, as possibilidades das atuais redes internas. Sendo um dos maiores benefícios para a quebra de barreiras, isto é, a mudança da cultura interna, pois é possível oferecer informação de forma rápida e simples, acessível até mesmo aos "leigos em informática".

$\mathrm{Na}$ Intranet, cada parte da empresa (departamento, divisão, em alguns casos, até mesmo os membros da equipe) cria sua própria "home page", tornando disponível, a todo e qualquer funcionário, seus produtos e serviços.

A utilização de novas tecnologias foi de importância vital para as rotinas administrativas - algumas das quais aboliu ou, para o processamento técnico - que revolucionou - (FIGUEIREDO, 1992). Em relação à Internet/Intranet, surgem novos pontos de discussões, enquanto outros já antigos, ganham novas perspectivas. Quais os produtos e serviços que serão colocados "on line" e, a que medida torná-los disponíveis? Qual será a nova relação entre o cliente e o profissional de informação, entre os profissionais da equipe de uma unidade de informação e, entre esta e a organização a que pertence? Como isto se ocorrerá? Que tipo de formação será exigida para suprir a demanda do mercado profissional? Estas são algumas das questões que os profissionais da informação, neste fim de milênio, têm diante de si.

\section{A DIDOTE NA INTRANET/CPRM}

Em 1997, por ocasião da exposição comemorativa de seus 28 anos, a CPRM Serviço Geológico do Brasil, entre outros lançamentos, divulgou para o seu público (tanto interno quanto externo) a sua Intranet. Mediante efetiva participação, a DIDOTE / Divisão de Documentação Técnica apresentou, pela primeira vez, sua "home page".

O processo de criação desta "home page" teve início quando do lançamento do "Programa CPRMNet", cujo o objetivo é atualizar a empresa no que se refere às novas tecnologias, principalmente as tecnologias da informação.

Como qualquer outra Intranet, em seu primeiro momento, ela se caracterizava por ser "estática", isto é, o que se tinha em papel passa-se para tela. Exemplos disto é a 
criação dos boletins de alerta "on line"(Sumários de Periódicos e Novas Aquisições), ou a divulgação de produtos impressos, como guias (de Referências e citações bibliográficas: com exemplos em Geociências e o Guia rápido para consulta às bases de dados). Outra característica deste momento é a divulgação da DIDOTE pela própria DIDOTE, isto é, falar de sua estrutura, organização, acervo, dados estatísticos, projetos atuais e futuros, etc.

Em um segundo momento, tenta-se não só melhorar a estética, o que é de fundamental importância para atrair cada vez mais "intranautas", como também, uma maior interação entre os usuários ("on line") e a DIDOTE. Já é possível requisitar cópias de artigos, tanto os divulgados "on line" quanto via COMUT ou BLDS, fazer reservas de livros, perguntas técnicas e solicitações de pesquisas bibliográficas.

Considerando um projeto experimental, a DIDOTE optou por tornar disponível, gradativamente, seus produtos e serviços, resultando em uma experiência de aprendizado. Já que todo o serviço de criação, padronização e manutenção ocorre dentro da própria Divisão, não havendo formalmente um suporte técnico de um analista de sistema ou programador. Mais uma vez exigese do profissional uma formação complementar, possibilitando-o a utilizar e dominar novas tecnologias da informação. Porém, desta vez de forma mais independente, não só assumindo o papel de coordenador dos trabalhos, mas também o próprio operador.

Com sete meses no ar, tem-se um novo desafio por objetivo: tornar o "site" da DIDOTE o máximo de interativo, para que se possa formar equipes virtuais entre os profissionais, neste caso analistas de informações. O que é de suma importância, para que possamos ultrapassar as barreiras ge- ográficas, já que contamos com 11 unidades regionais espalhadas por todo território nacional e assim, em tempo real, trabalhar em projetos em comum.

\section{CONCLUSÕES}

Para sobreviver nos tempos modernos da "Era da Informação", é necessário estar mais do que bem informado, é preciso estar aberto e aceitar as mudanças; visualizar as tendências e sair na frente. Todo este processo nos coloca em xeque, tanto como profissionais quanto como indivíduos. O domínio de informações sempre conferiu poder e "status" às pessoas. O acesso às informações, que antes era privilégio de poucos, está cada vez mais democrático. Dados e informações tornam-se cada vez mais dinâmicos, mais acessíveis a todos, porém, de uma forma maciça e caótica. $O$ maior e melhor exemplo disto é a Internet, o que difere da Intranet, já que esta é criada com um universo previamente definido - a empresa. Agora, o desafio é saber aprender e buscar habilidades necessárias para antecipar-se às mudanças. Não se pode mais ter as unidades de informação, como templos de guarda de documentos e sim, como unidades de interface entre a informação e o usuário, adaptando-se e criando de forma qualitativa e criativa novos instrumentos de ligação. Quem não se adequar ao novo modelo, corre o risco de ser esquecido no "túnel do tempo"

\section{REFERÊNCIAS}

FIGUEIREDO, Nice M. Tópicos modernos em Ciência da Informação. São Paulo: Centro Cultural Teresa D'Ávila, 1994. 145p.

FREIRE, Isa Maria. Informação; consciência possível; campo. Um exercício com construtors teóricos. Ciência da Informação, 
Brasília, v.24, n.1, p.84-88, jan./abr. 1995.

GONZÁLEZ DE GÓMEZ, Maria Nélida. Informação: a partir de que perguntas, em direção de que respostas? R.Bibliotecon. de Brasília, Brasília, v.19, n.2, p.257-268, jul./ dez. 1995.

GUINCHAT, Claire, MENOU, Michel. Introdução às ciências e técnicas da informação e documentação. Brasília: IBICT, 1994. 540p.

LEVACON, Marília. Bibliotecas virtuais: $(r)$ evolução? Ciência da Informação, Brasília, v.26, n.2, p.125-135, maio/ago. 1997.

MARCHIORI, Patrícia Zeni. "Ciberteca" ou biblioteca virtual: uma perspectiva de gerenciamento de recursos de informação. Ciência da Informação, Brasília, v.26, n.2, p.115-124, maio/ago. 1997.

MÜLLER, Mary Stela. Mudar é preciso ... Inf.\&Inf., Londrina, v.0, n.0, p.42-46, jul./dez. 1995

RODRIGUEZ REYES, Victorico. Los servicios de información en el próximo milenio. Ciência da Informação, Brasília, v.26, n.1, p.78-87, jan./abr. 1997.

ROSETO, Marcia. Os novos materiais bibliográficos e a gestão da informação: livro eletrônico e biblioteca eletrônica na América Latina e Caribe. Ciência da Informação, Brasília, v.26, n.1, p.54-64, jan./abr. 1997.

TEIXEIRA, Cenivalda Miranda de Sousa, SCHIEL, Ulrich. A Internet e seu impacto nos processos de recuperação da informação. Ciência da Informação, Brasília, v.26, n.1, p.65-71, jan./abr. 1997.

VALENTIM, Marta L. P. Assumindo um novo paradigma na Biblioteconomia. Inf. \&Inf., Londrina, v.0, n.0, p.2-6, jul./dez. 1995.
VALLE, Benjamin de Medeiros. Tecnologia da informação no contexto organizacional. Ciência da Informação, Brasília, v.25, n.1, p.7-11, jan./abr. 1996.

WURMAN, Richard Saul. Ansiedade de Informação ... São Paulo: Cultural, 1991. 380p.

\section{Claudia Lopes}

Analista de Informações - CPRM - Serviço Geológico do Brasil

clopes@cristal.cprm.gov.br

\section{Title}

New Technologies: the Intranet as a factor of modification of the information centers

\section{Abstract}

Times have been really lately and consequently there has been a demand for highly individuals. As for the area of information, this procewss should not be ignored since the survival of the information centers as well as the accomplishment of their tasks depend on it. That is why the information professionals should rethink their activities and attitudes. In this context, Intranet is considered as an important tool for dissemination and improvement of the services and products provided for the users by the information centers.

\section{Keywords}

New technologies; Information technology; Internet; Intranet; Information Professionals

\section{Titulo}

Nuevas tecnologias: la Intranet como factor de 
cambio para las unidades de información.

\section{Resumen}

En esta última década, tanto las organizaciones cuanto los seres humanos viven en una época de cambios cada vez más rápidos, exigiendo a nivel de individuos y de profesionales una disponibilidad de aprender y de adaptarse a esos nuevos tiempos. Con relación al área de la información, este proceso no debe ser ignorado, ya que de él depende la sobrevivencia tanto de las unidades de información cuanto del efectivo ejercicio de sus actividades. Se hace necesário, más que nunca, que los profesionales de la información vuelvan a pensar en sus actividades y posiciones. Dentro de este contexto surge la posibilidad de utilizar la Intranet como un instrumento de propagación y mejoría de la atención ofrecida, productos y servicios ofrecidos por las unidades de información.

\section{Palabras-Clave}

Nuevas Tecnologías; Tecnología de la Información; Internet; Intranet; Profesional de la Información

\section{Resumo}

Mostra a importância da tecnologia de informação na atualidade, com ênfase em alguns setores chaves ligados à comercialização de produtos. Apresenta os principais avanços e limitações da combinação de recursos de telecomunicações e de tecnologia de informação nos principais elos de algumas cadeias de comercialização. Apesar do grande potencial dessa nova tecnologia é importante que haja cooperação entre os diversos setores dessa cadeia para permitir sua plena atuação em todos os ramos da comercialização.

Palavras-chave

Satélite; Tecnologia de Informação;Acesso à Informação; Comercialização; Transporte. 